\title{
Enhanced Sulfur Dioxide Adsorption in UiO-66 Through Crystal Engineering and Chalcogen Bonding
}

Ian Walton, ${ }^{+}$Carmen Chen, ${ }^{+}$Jessica M. Rimsza, ${ }^{\ddagger}$ Tina M. Nenoff,, Krista S. Walton ${ }^{+, *}$

+ School of Chemical \& Biomolecular Engineering, Georgia Institute of Technology, Atlanta, Georgia 30332, USA.

\$ Geochemistry Department, Sandia National Laboratories, Albuquerque, New Mexico 87185, USA.

§ Material, Physical, and Chemical Sciences Center, Sandia National Laboratories, Albuquerque, NM 87185, USA.

Table of Contents

PXRD Data

Thermographic Analysis Data

Physisorption Data

$\mathrm{SO}_{2}$ Micro-Breakthrough Data

NMR Data

3-dimethylaminopropanoic (DMAP) formation

Computational Data

Citations
Page

S2-S4

S5-S7

S8-S10

S11-S14

S15-S19

S19

S20-S22

S23 


\section{Powder X-ray Diffraction}

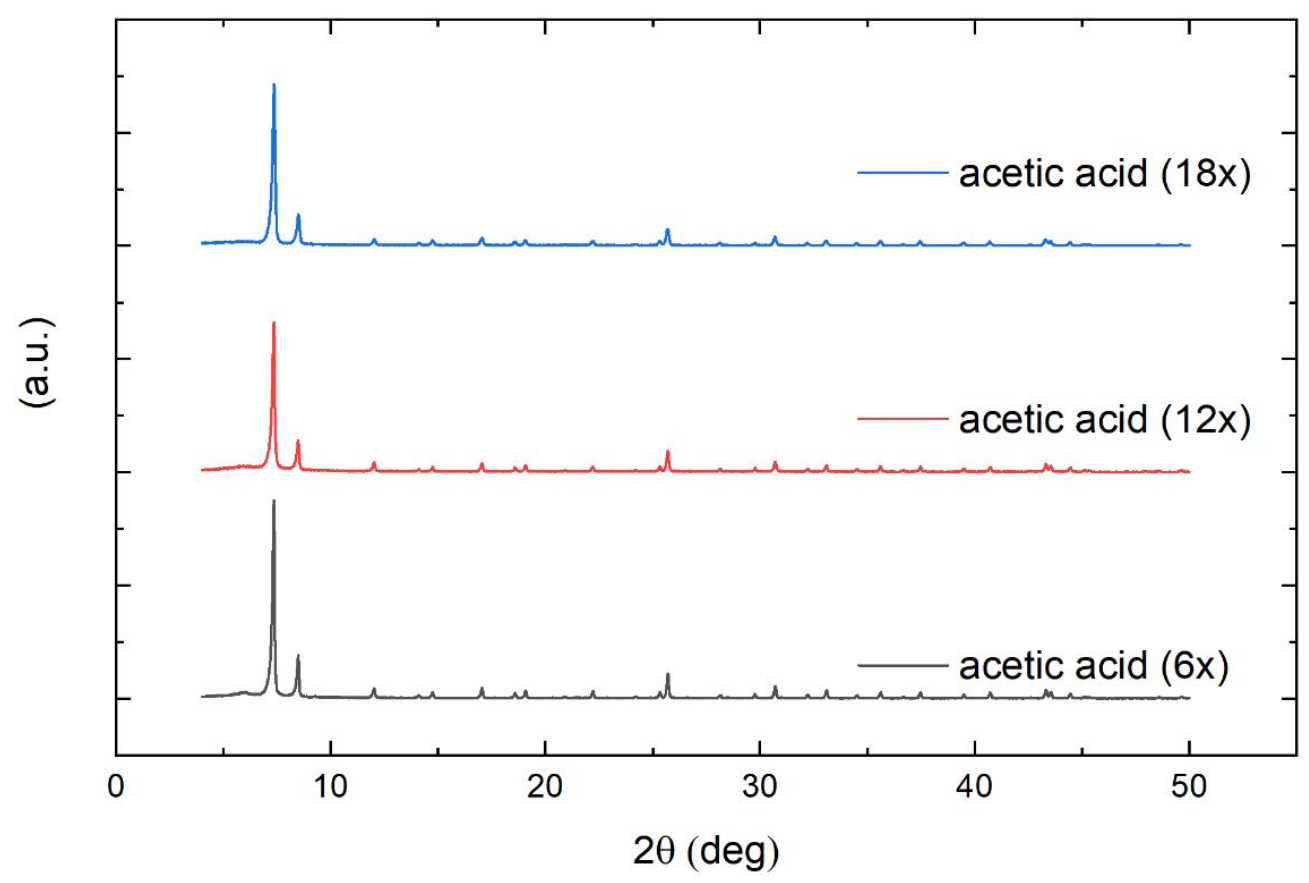

Figure S01: PXRD patterns of acetic acid modulated Ui0-66. Modulator equivalent to linker: 6:1 (black), 12:1 (red), and 18:1 (blue). 


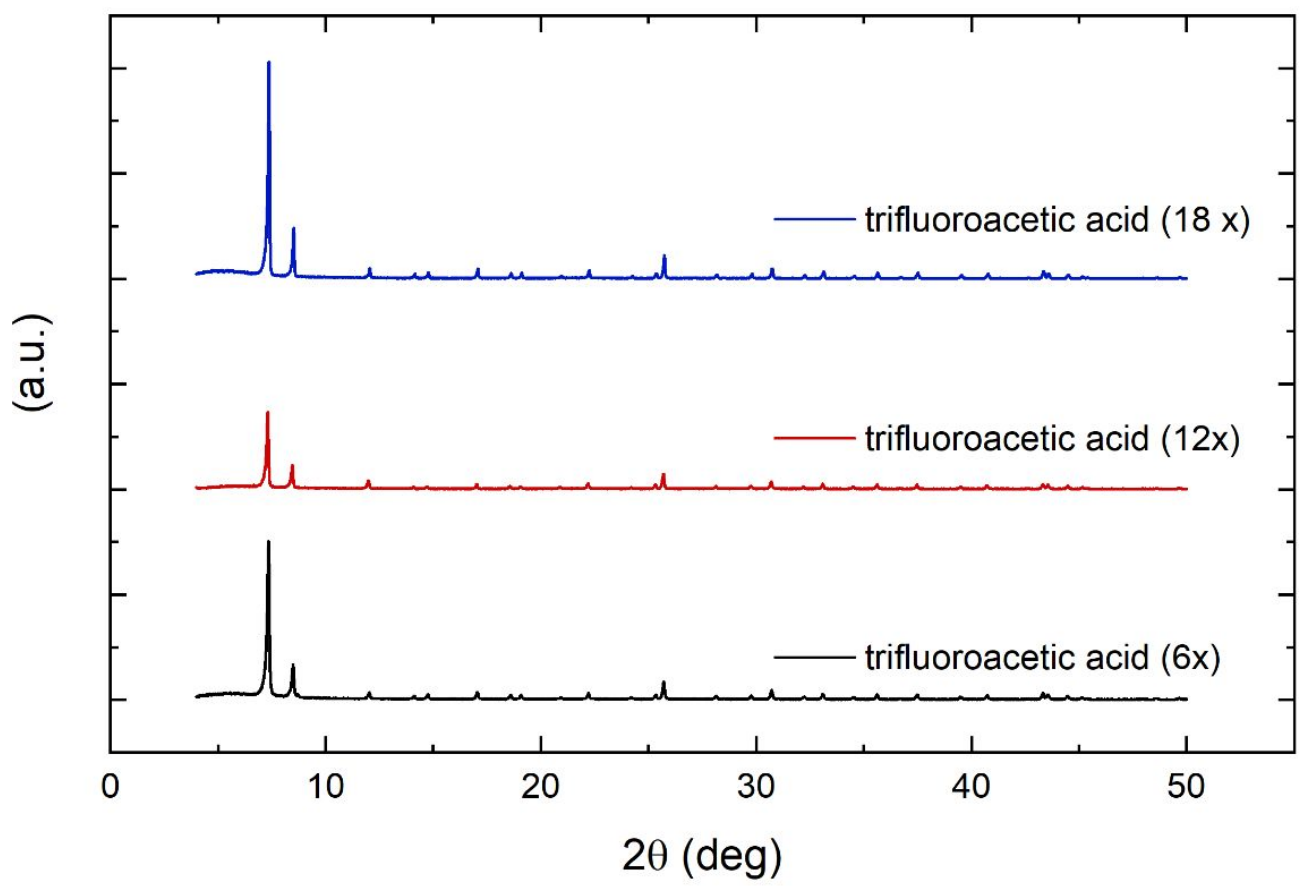

Figure SO2: PXRD patterns of trifluoroacetic acid modulated UiO-66. Modulator to linker ratios: 6:1 (black), 12:1 (red), and 18:1 (blue).

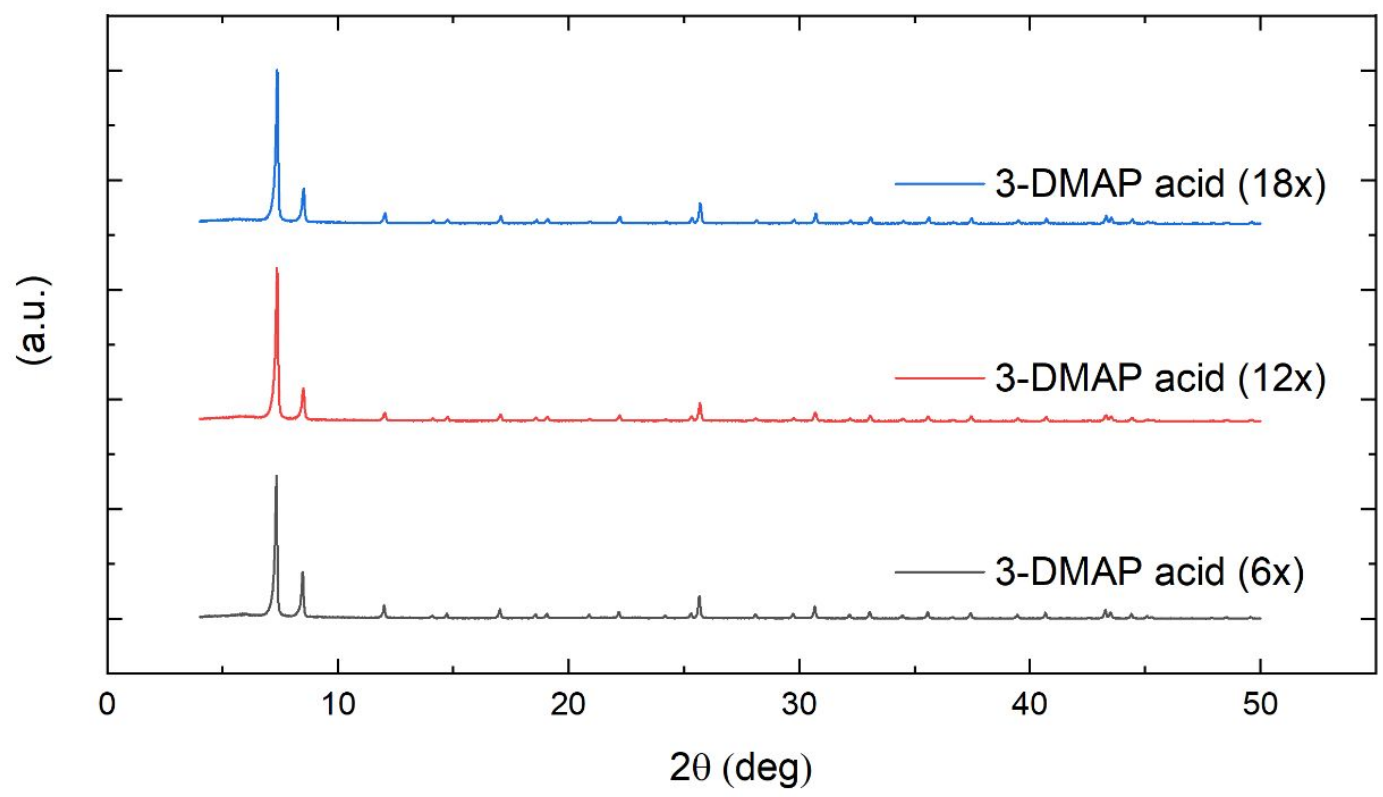

Figure S03: PXRD patterns of acrylic acid modulated UiO-66. Modulator to linker ratios: 6:1 (black), 12:1 (red), and 18:1 (blue). 


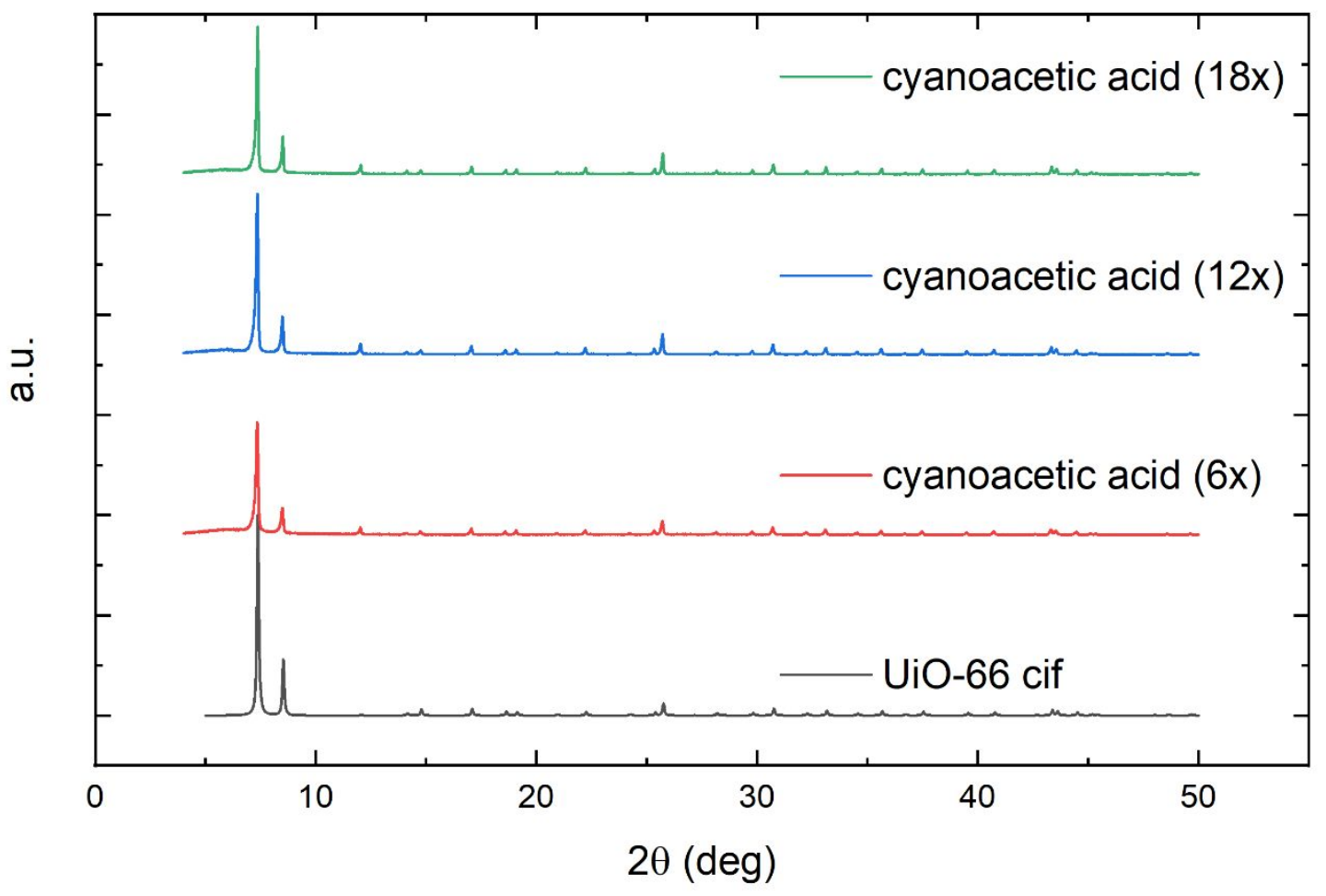

Figure S04: PXRD patterns of cyanoacetic acid modulated UiO-66. Modulator to linker ratios: 6:1 (black), 12:1 (red), and 18:1 (blue). The reference CIF was obtained from the literature. ${ }^{1}$ 


\section{Thermogravimetric Analysis}

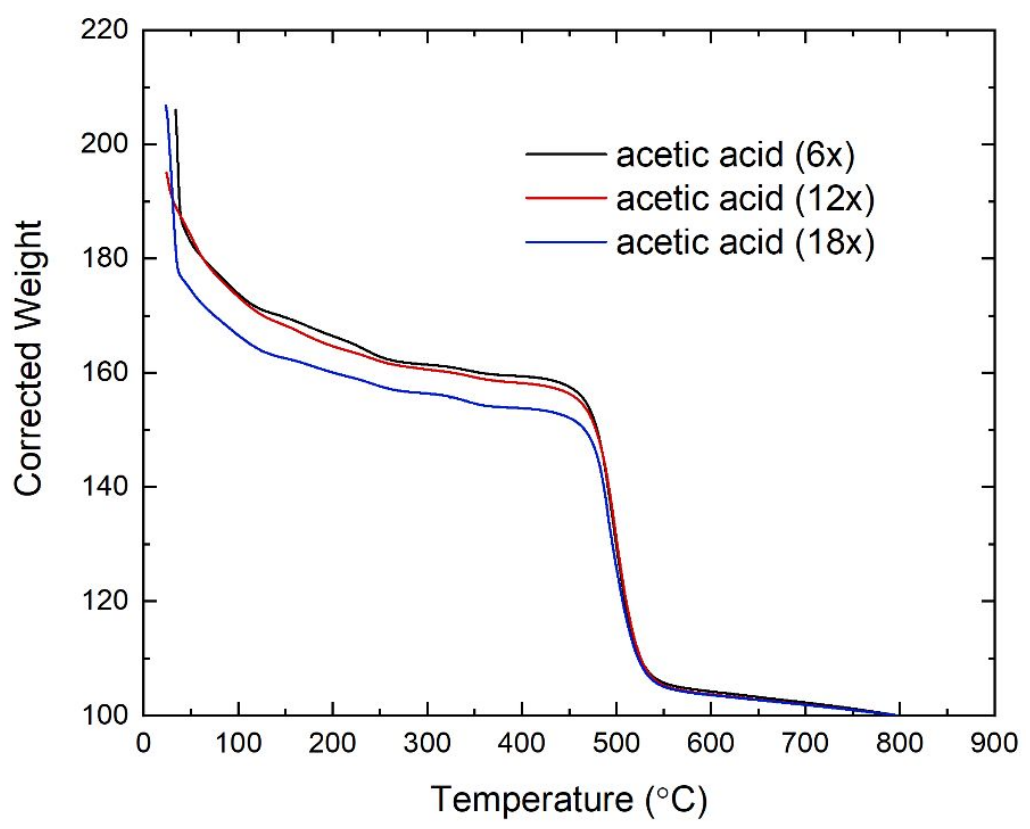

Figure S05: Thermogravimetric analysis of acetic acid modulated UiO-66.

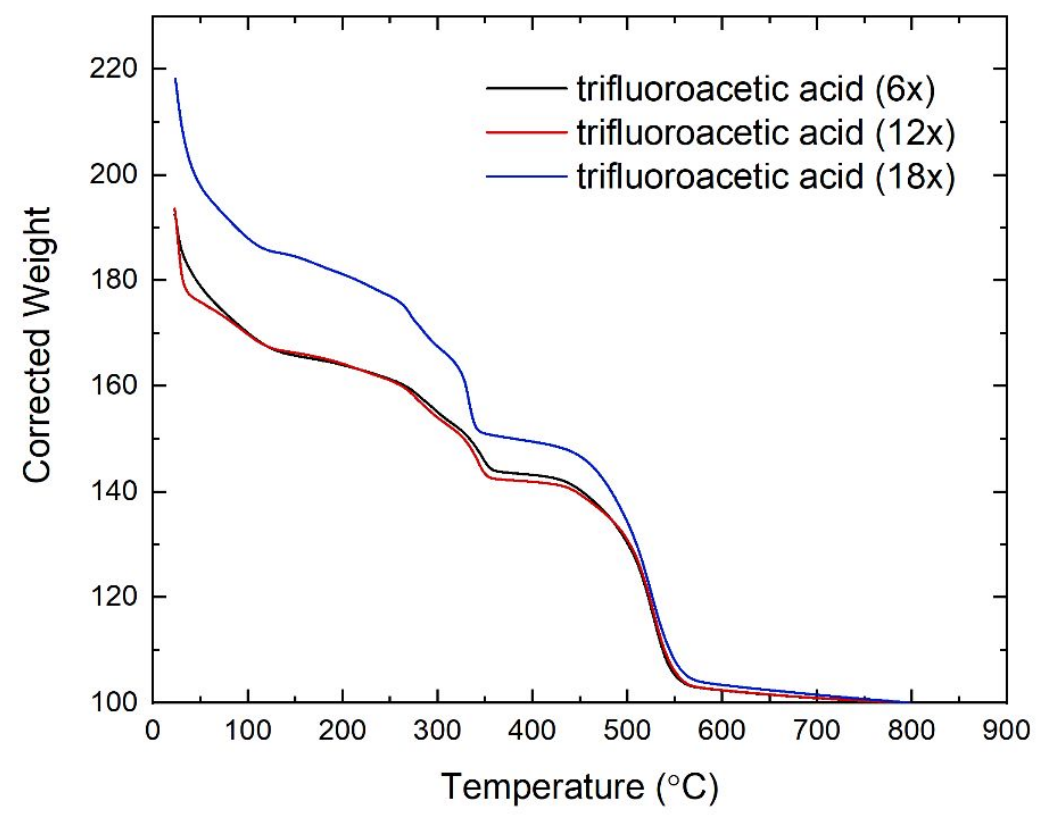

Figure S06: Thermogravimetric analysis of trifluoroacetic acid modulated UiO-66. 


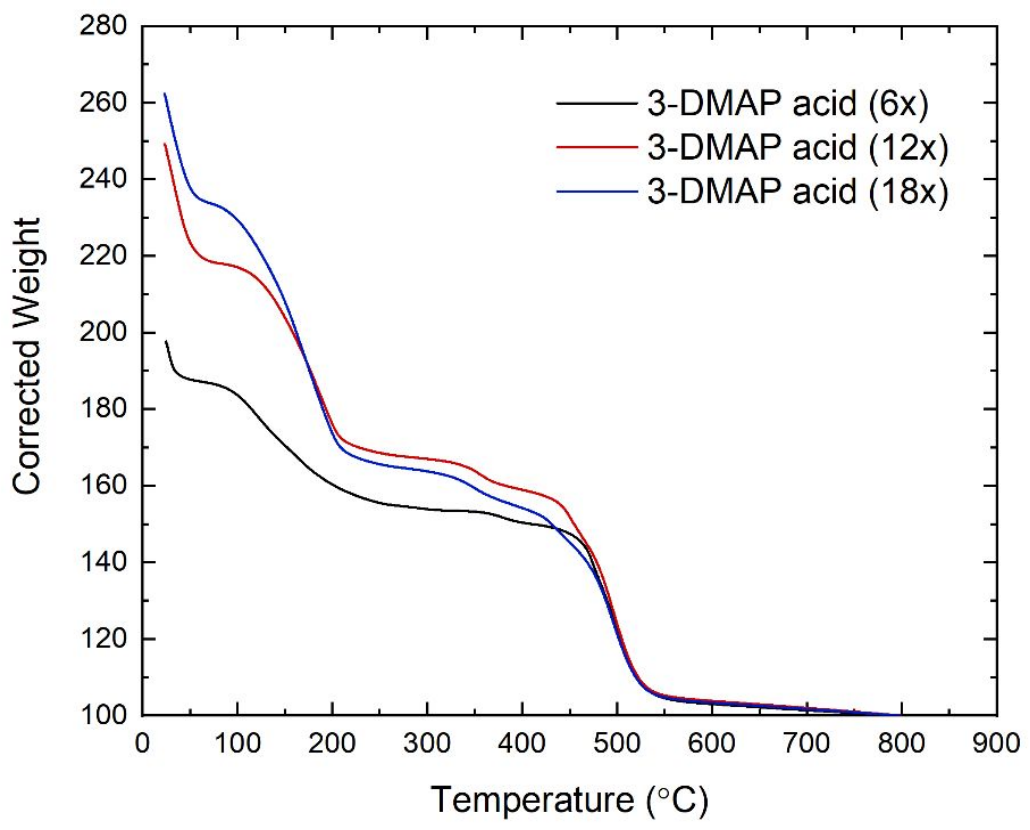

Figure S07: Thermogravimetric analysis of acrylic acid modulated UiO-66.

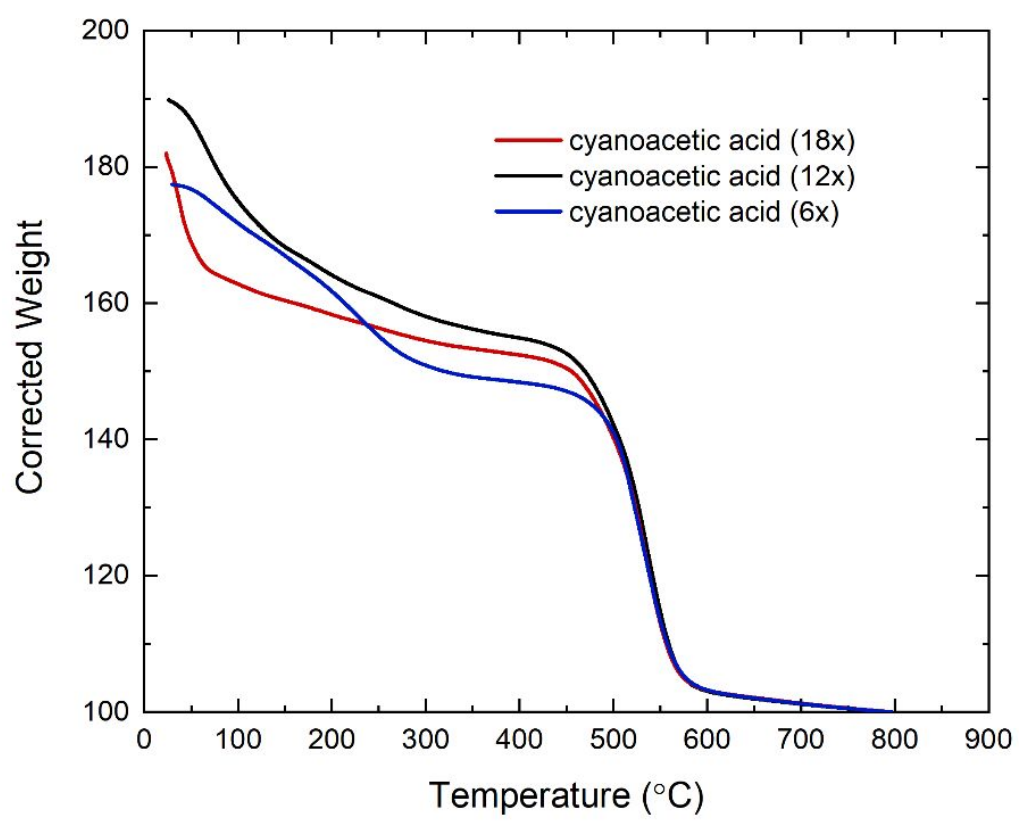

Figure S08: Thermogravimetric analysis of cyanoacetic acid modulated UiO-66. 
Table S01: Concentrations of the organic acid components of modulated UiO-66 samples. Concentrations of organic components are based upon the mass of the TGA samples, the TGA data, and the ratio of linker to formate and linker to residual modulator from digestion NMR data.

\begin{tabular}{|c|c|c|c|c|c|}
\hline Modulator & Mod. Equiv. & $\begin{array}{l}\text { Zr atom Conc. } \\
\text { (mmol/g) }\end{array}$ & $\begin{array}{l}\text { Linker Conc. } \\
\text { (mmol/g) }\end{array}$ & $\begin{array}{l}\text { Mod. Conc. } \\
\text { (mmol/g) }\end{array}$ & $\begin{array}{l}\text { Formate Conc. } \\
(\mathrm{mmol} / \mathrm{g})\end{array}$ \\
\hline \multirow[t]{3}{*}{ acetic acid } & 6 & 4.386 & 2.151 & 0.1106 & 0.0796 \\
\hline & 12 & 3.816 & 1.829 & 0.0745 & 0 \\
\hline & 18 & 4.611 & 2.046 & 0.1576 & 0.0471 \\
\hline \multirow{3}{*}{$\begin{array}{l}\text { trifluoroacetic } \\
\text { acid }\end{array}$} & 6 & 4.435 & 1.565 & 0.2032 & 0.0426 \\
\hline & 12 & 4.585 & 1.576 & 0.4855 & 0.1304 \\
\hline & 18 & 4.141 & 1.675 & 0.9013 & 0.2071 \\
\hline \multirow{3}{*}{$\begin{array}{l}\text { 3-DMAP acid } \\
\text { (acrylic acid) }\end{array}$} & 6 & 4.340 & 1.658 & 0.1078 & 1.119 \\
\hline & 12 & 3.740 & 1.805 & 0.8918 & 0.8069 \\
\hline & 18 & 3.483 & 1.571 & 1.279 & 1.150 \\
\hline \multirow{3}{*}{$\begin{array}{l}\text { cyanoacetic } \\
\text { acid }\end{array}$} & 6 & 4.573 & 1.819 & 0.0287 & 0.2205 \\
\hline & 12 & 4.275 & 1.925 & 0.0155 & 0.2176 \\
\hline & 18 & 4.459 & 1.922 & 0.0932 & 0.0523 \\
\hline
\end{tabular}

Calculation of the residual modulator concentration was accomplished through the technique detailed by Shearer et al. ${ }^{2}$ The plateau used for the calculation of linker from the TGA was taken at $425^{\circ} \mathrm{C}$ for all modulators except acrylic acid, for which $415^{\circ} \mathrm{C}$ was used for the 6 and $12 \mathrm{eq}$ samples, and $400{ }^{\circ} \mathrm{C}$ for the 18 eq sample. Ratios between the terephthalate linker and the residual modulator were obtained from digestion NMR, sample spectra detailed below. 


\section{Isothermal Adsorption for BET Surface Area Analysis}

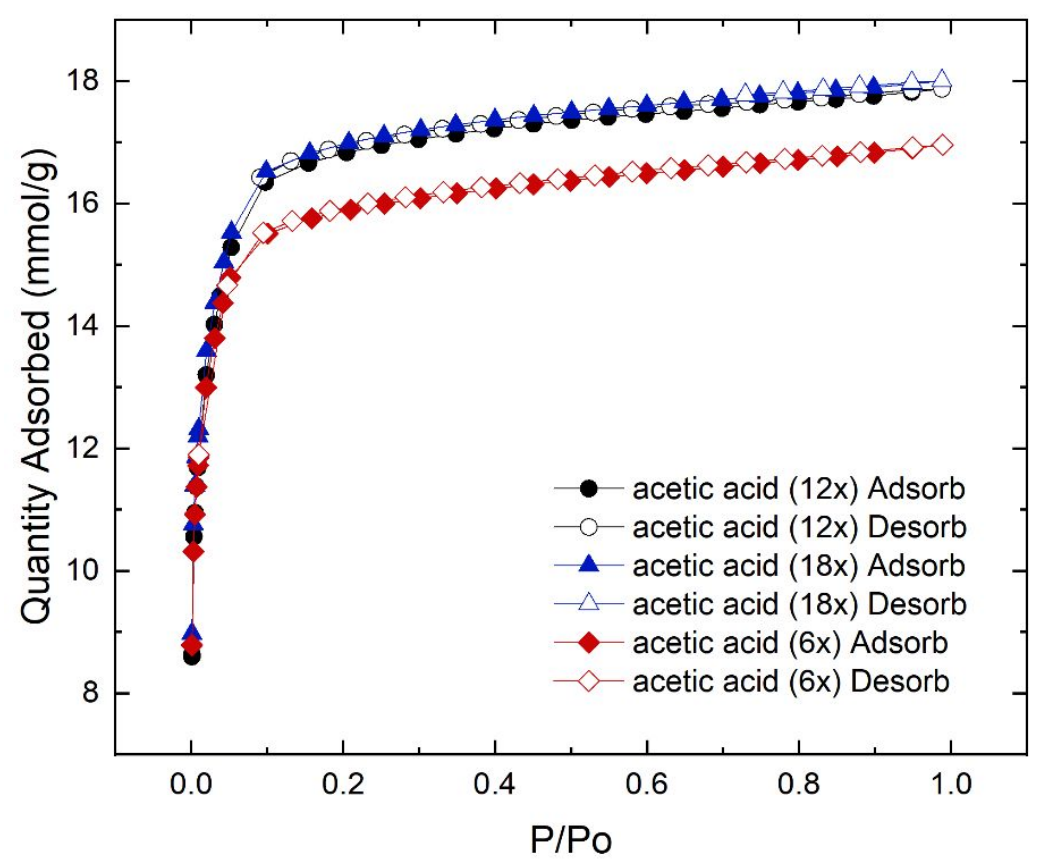

Figure S09: Argon physisorption at $87.3 \mathrm{~K}$ for BET surface area determination of acetic acid modulated UiO-66

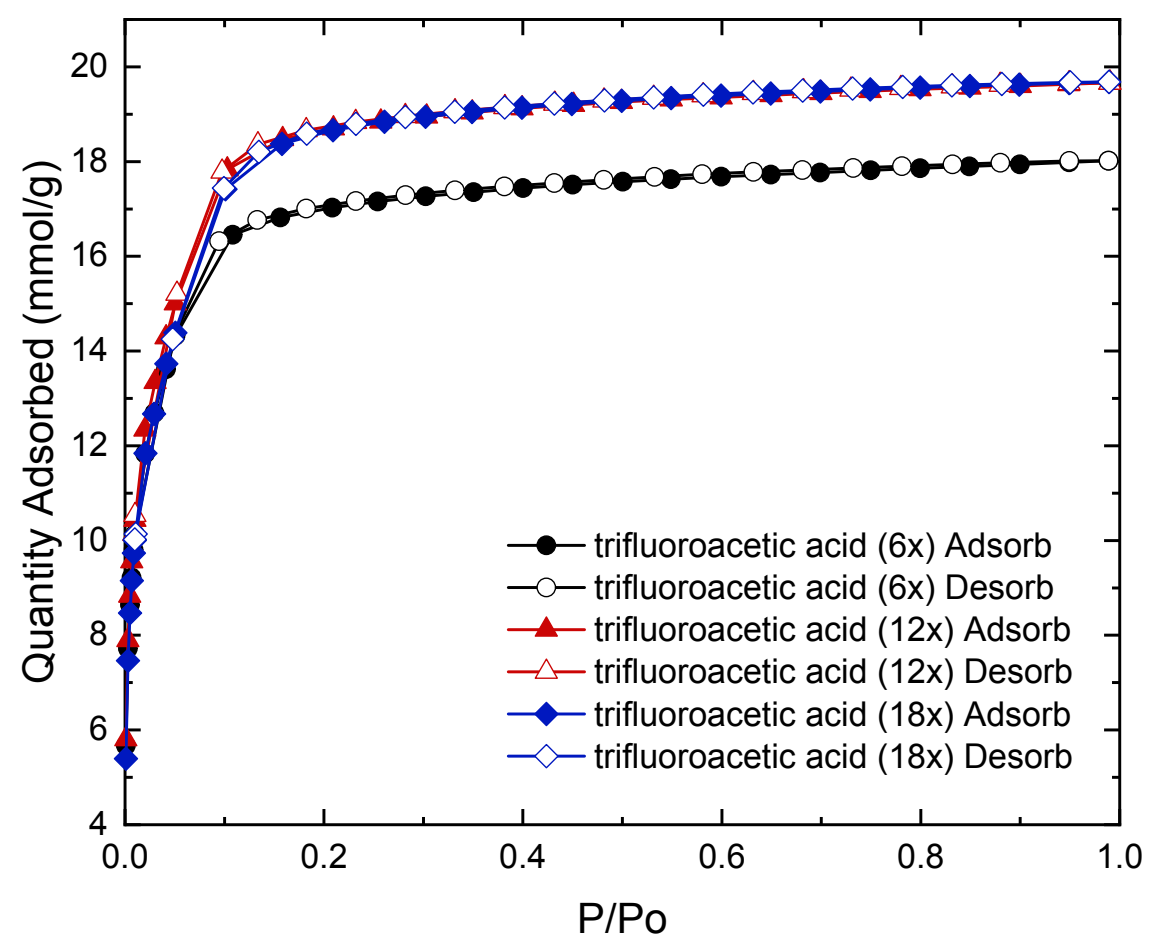

Figure S10: Argon physisorption at $87.3 \mathrm{~K}$ for BET surface area determination of trifluoroacetic acid modulated UiO-66 


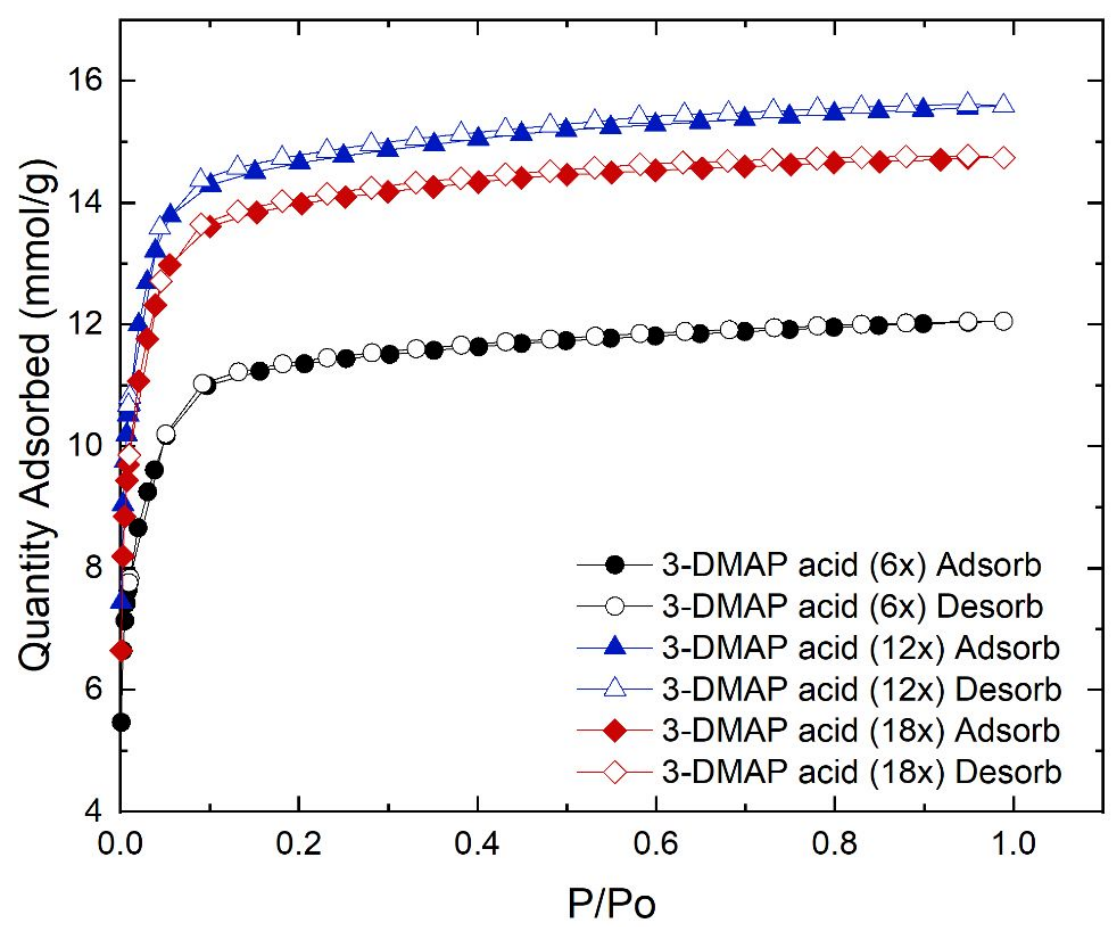

Figure S11: Argon isothermal physisorption measurements for BET surface area analysis of acrylic acid modulated UiO-66.

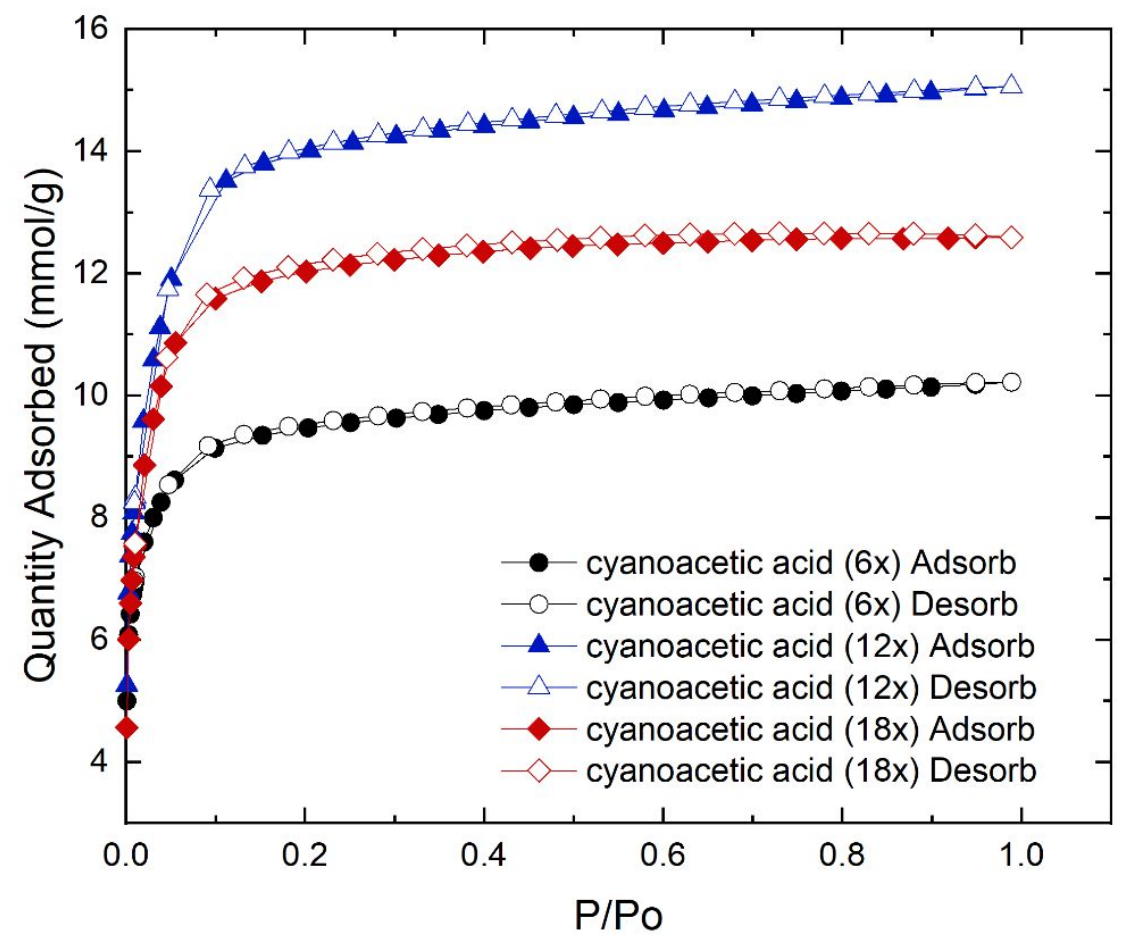

Figure S12: Argon isothermal physisorption measurements for BET surface area analysis of cyanoacetic acid modulated UiO-66. 
Table S02: BET surface area of modulated UiO-66 samples determined from argon physisorption at $87.3 \mathrm{~K}$.

\begin{tabular}{|c|c|c|}
\hline Modulator & $\begin{array}{l}\text { Mod. } \\
\text { Equiv. }\end{array}$ & Surface Area $\left(\mathrm{m}^{2} / \mathrm{g}\right)$ \\
\hline “ideal” & $\mathrm{n} / \mathrm{a}$ & 994.7 \\
\hline \multirow[t]{3}{*}{ acetic acid } & 6 & 1222 \\
\hline & 12 & 1284 \\
\hline & 18 & 1299 \\
\hline \multirow{3}{*}{$\begin{array}{l}\text { trifluoroacetic } \\
\text { acid }\end{array}$} & 6 & 1286 \\
\hline & 12 & 1398 \\
\hline & 18 & 1363 \\
\hline \multirow{3}{*}{$\begin{array}{l}\text { 3-DMAP acid } \\
\text { (acrylic acid) }\end{array}$} & 6 & 867 \\
\hline & 12 & 1145 \\
\hline & 18 & 1077 \\
\hline \multirow{3}{*}{$\begin{array}{c}\text { cyanoacetic } \\
\text { acid }\end{array}$} & 6 & 717 \\
\hline & 12 & 1053 \\
\hline & 18 & 922 \\
\hline
\end{tabular}




\section{Dynamic Adsorption Data}

For all dynamic adsorption data, a home built micro-breakthrough system was used. The system utilized a California Analytical Instruments detector (600SC FTIR) to analyze the post bed gas stream to determine when full sample saturation had been achieved, the "dead volume" was obtained from a $1 \mathrm{~cm}$ bed of $10 \mu \mathrm{m}$ glass beads, using the same $\mathrm{SO}_{2}$ source as the experiments at the same temperature and flow rate. The instrument was automated through the use of pneumatically controlled valve actuators, controlled through a custom LabView program. Temperature control of the sample for activation and throughout the breakthrough run was accomplished with a Polyscience heating/chilling recirculating bath (AP7LR) controlled through an external thermocouple. The bed was wrapped in a heating/cooling coil, with the thermocouple embedded between the coil and the sample tube. The activation and sample run temperatures were controlled through the same LabView program as the rest of the instrument.

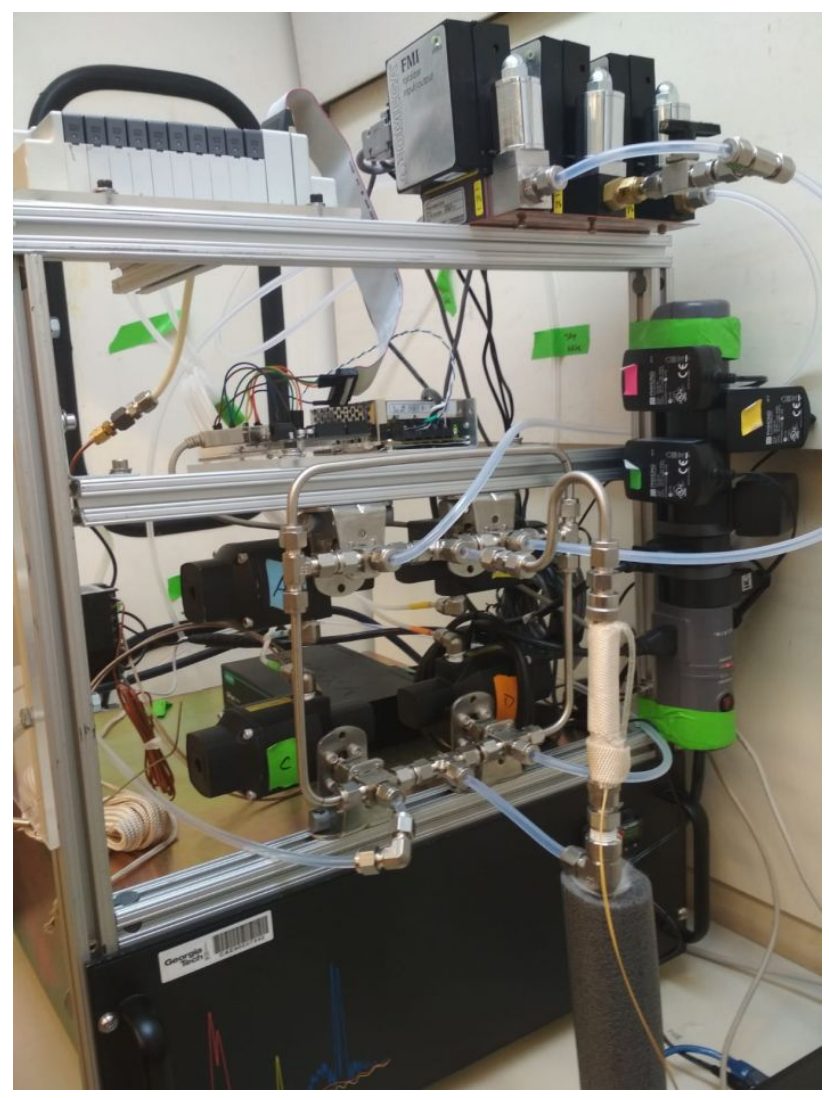

Figure S13: Home-built automated breakthrough system utilized for all dynamic breakthrough experiments. 


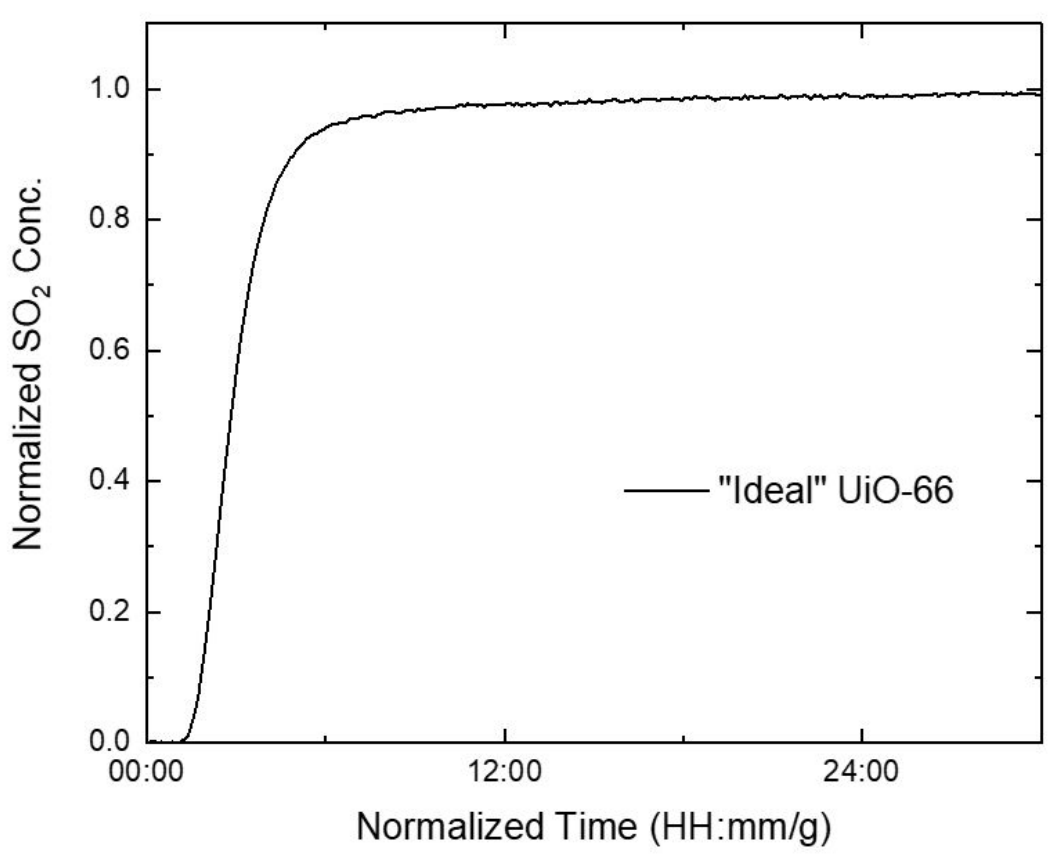

Figure S14: Dynamic adsorption of 950 ppm of SO2 in balance nitrogen at $20 \mathrm{ml} / \mathrm{min}$ for an "ideal" UiO-66 sample.

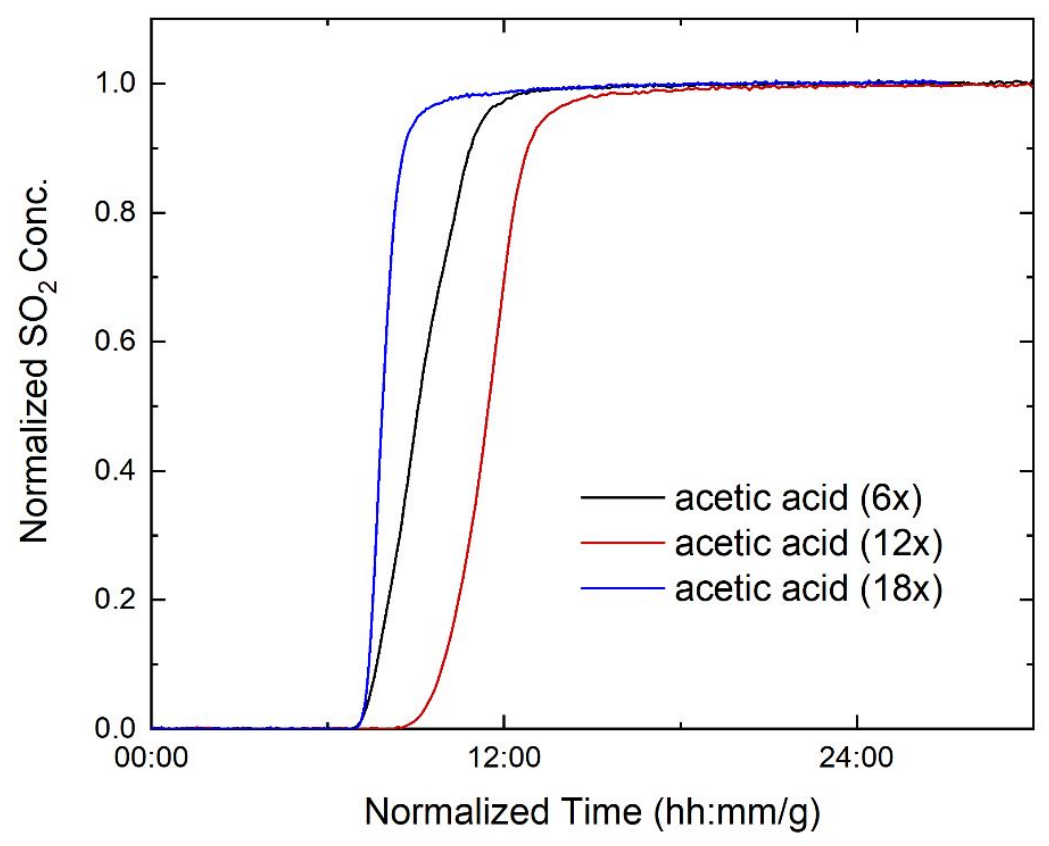

Figure S15: Dynamic adsorption of $950 \mathrm{ppm} \mathrm{SO}_{2}$ in balance nitrogen at $20 \mathrm{ml} / \mathrm{min}$ for acetic acid modulated UiO-66 samples. 


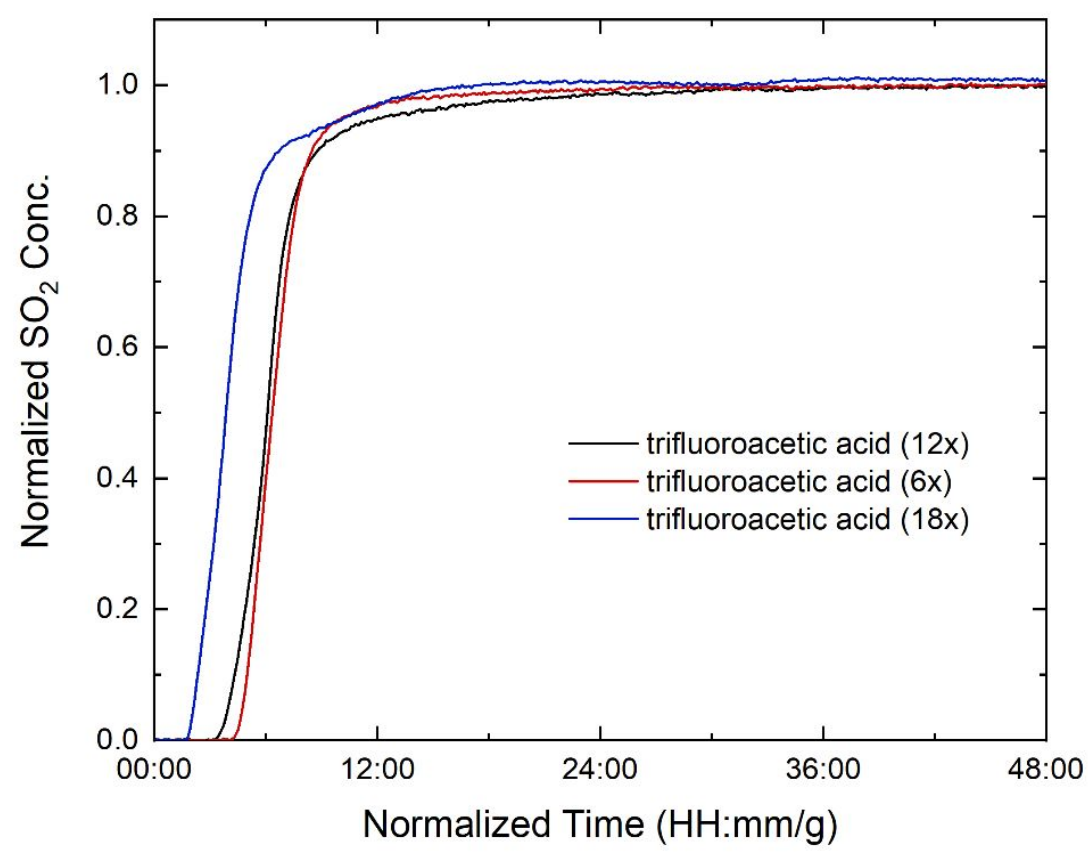

Figure S16: Dynamic adsorption of $950 \mathrm{ppm} \mathrm{SO}_{2}$ in balance nitrogen at $20 \mathrm{ml} / \mathrm{min}$ for trifluoroacetic acid modulated UiO-66 samples.

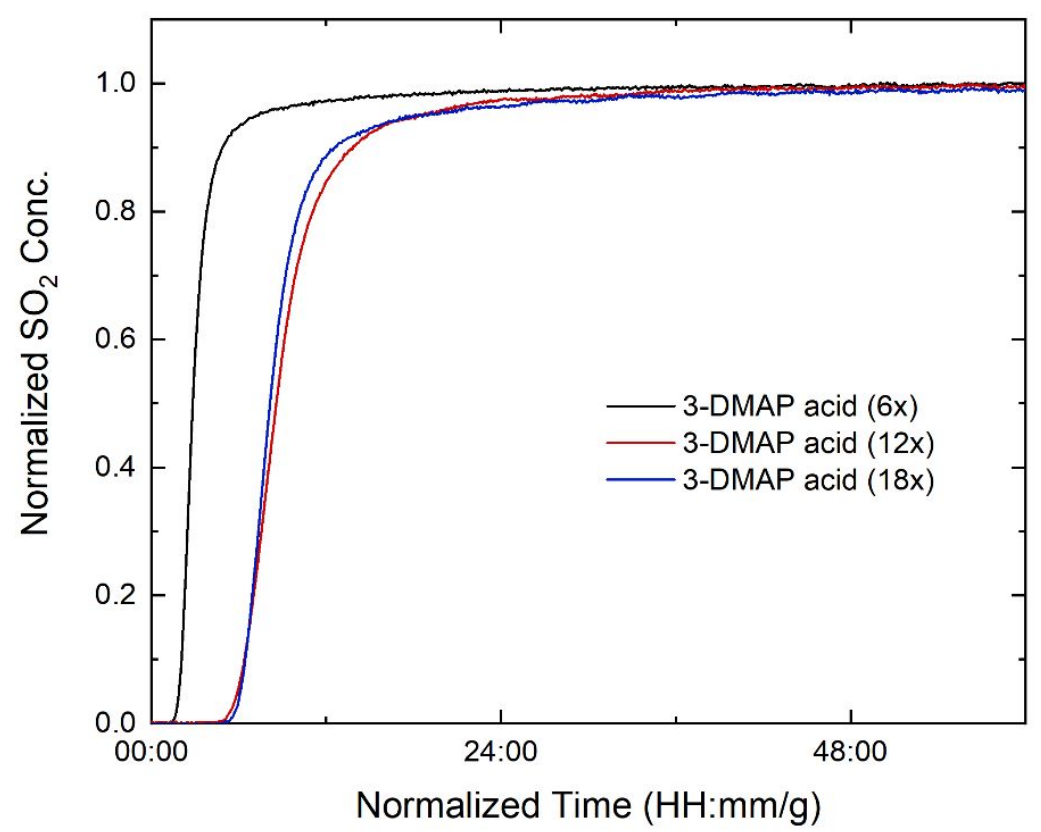

Figure S17: Dynamic adsorption of $950 \mathrm{ppm} \mathrm{SO}_{2}$ in balance nitrogen at $20 \mathrm{ml} / \mathrm{min}$ for acrylic acid modulated UiO-66 samples. 


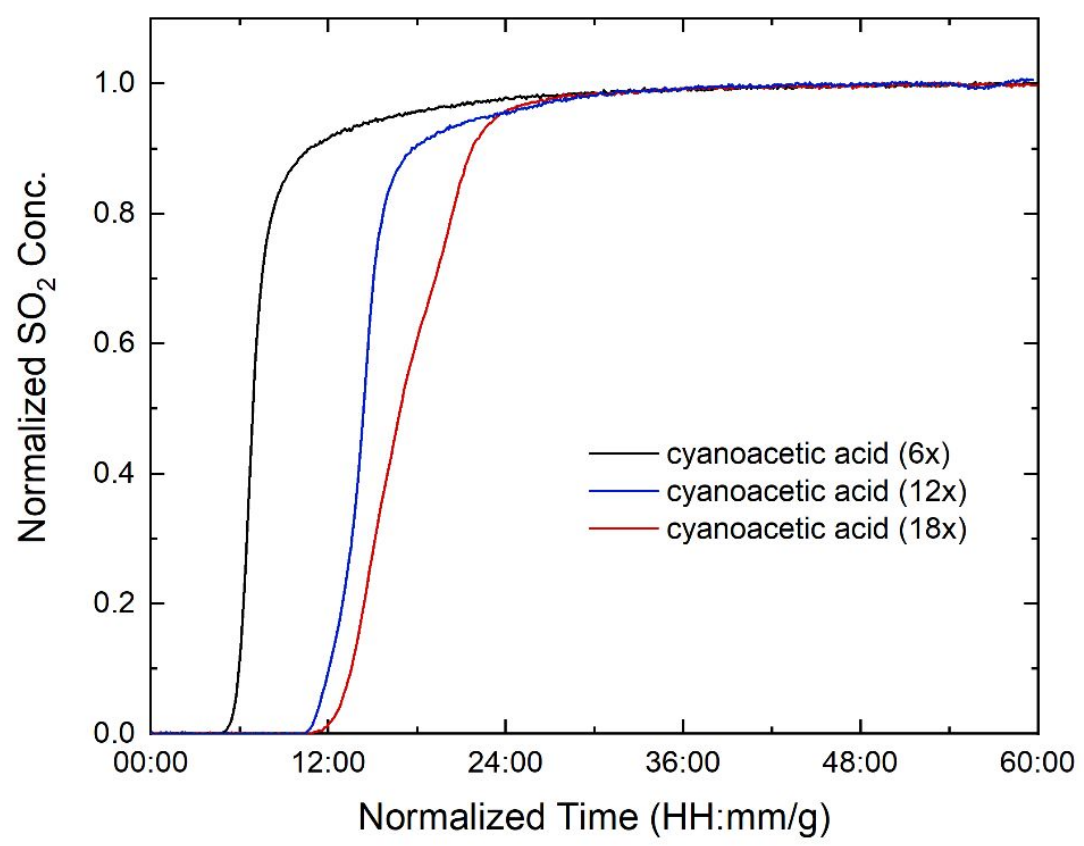

Figure S18: Dynamic adsorption of $950 \mathrm{ppm} \mathrm{SO}_{2}$ in balance nitrogen at $20 \mathrm{ml} / \mathrm{min}$ for cyanoacetic acid modulated UiO-66 samples. 
Table S03: Dynamic $\mathrm{SO}_{2}$ capacity at $950 \mathrm{ppm} \mathrm{SO}_{2}$ and residual modular capacity for comparison.

\begin{tabular}{|c|c|c|c|}
\hline Modulator & Mod. Equiv. & $\begin{array}{l}\text { Dynamic Capacity } \\
(\mathrm{mmol} / \mathrm{g})\end{array}$ & Mod. Conc. (mmol/g) \\
\hline “ideal" & $\mathrm{n} / \mathrm{a}$ & 0.1209 & \\
\hline \multirow[t]{3}{*}{ acetic acid } & 6 & 0.4279 & 0.1106 \\
\hline & 12 & 0.5217 & 0.0745 \\
\hline & 18 & 0.3779 & 0.1576 \\
\hline \multirow[t]{3}{*}{ trifluoroacetic acid } & 6 & 0.2949 & 0.2032 \\
\hline & 12 & 0.297 & 0.4855 \\
\hline & 18 & 0.1557 & 0.9013 \\
\hline \multirow{3}{*}{$\begin{array}{l}\text { 3-DMAP acid } \\
\text { (acrylic acid) }\end{array}$} & 6 & 0.1497 & 0.1078 \\
\hline & 12 & 0.4713 & 0.8918 \\
\hline & 18 & 0.4891 & 1.279 \\
\hline \multirow[t]{3}{*}{ cyanoacetic acid } & 6 & 0.3746 & 0.0287 \\
\hline & 12 & 0.7192 & 0.0155 \\
\hline & 18 & 0.8336 & 0.0932 \\
\hline
\end{tabular}




\section{NMR Data}

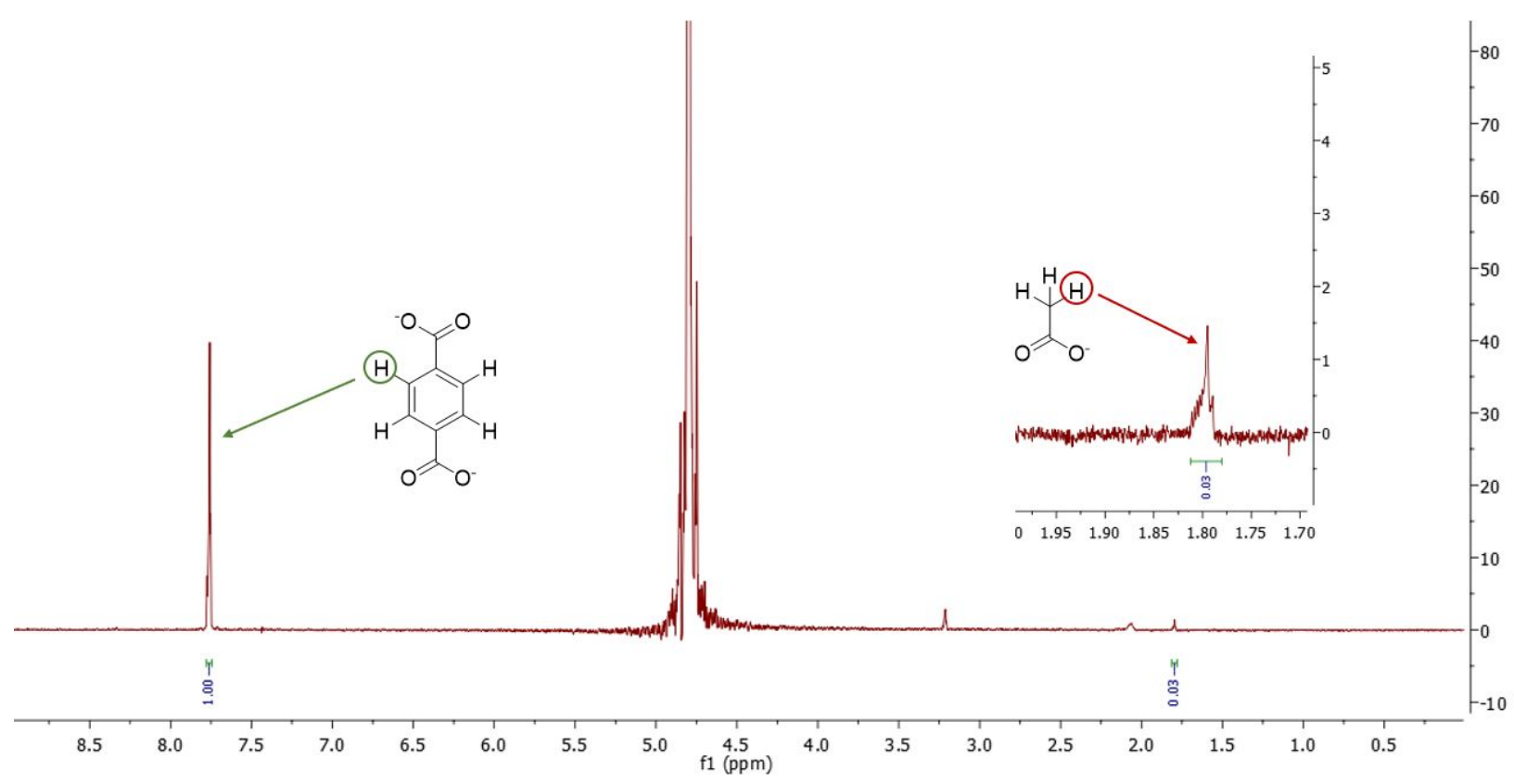

Figure S19: ${ }^{1} \mathrm{H}$ NMR spectrum of UiO-66 modulated with 12 eq of acetic acid following digestion with $\mathrm{NaOH}$ in D20. Insert highlights the residual modulator peaks associated with the residual acetic acid left coordinated within the lattice. All residual modulator quantifications calculations utilized these peaks for samples synthesized with an acetic acid modulator. 


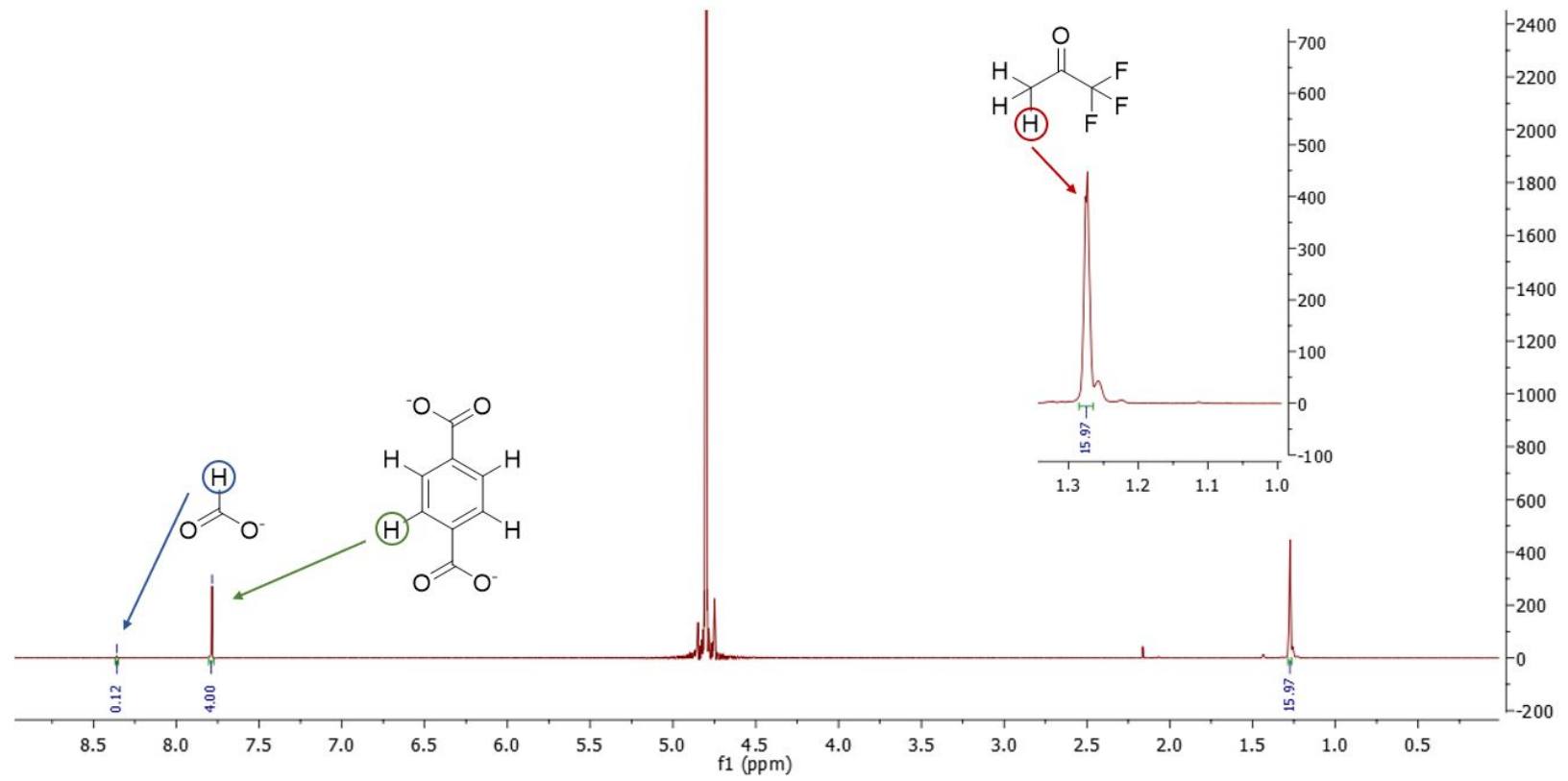

Figure S20: ${ }^{1} \mathrm{H}$ NMR spectrum of UiO-66 modulated with 18 eq of trifluoroacetic acid following digestion with $\mathrm{NaOH}$ in D2O. Insert highlights the residual modulator peaks associated with the residual trifluoroacetic acid left coordinated within the lattice. All residual modulator quantifications calculations utilized these peaks for samples synthesized with a trifluoroacetic acid modulator.

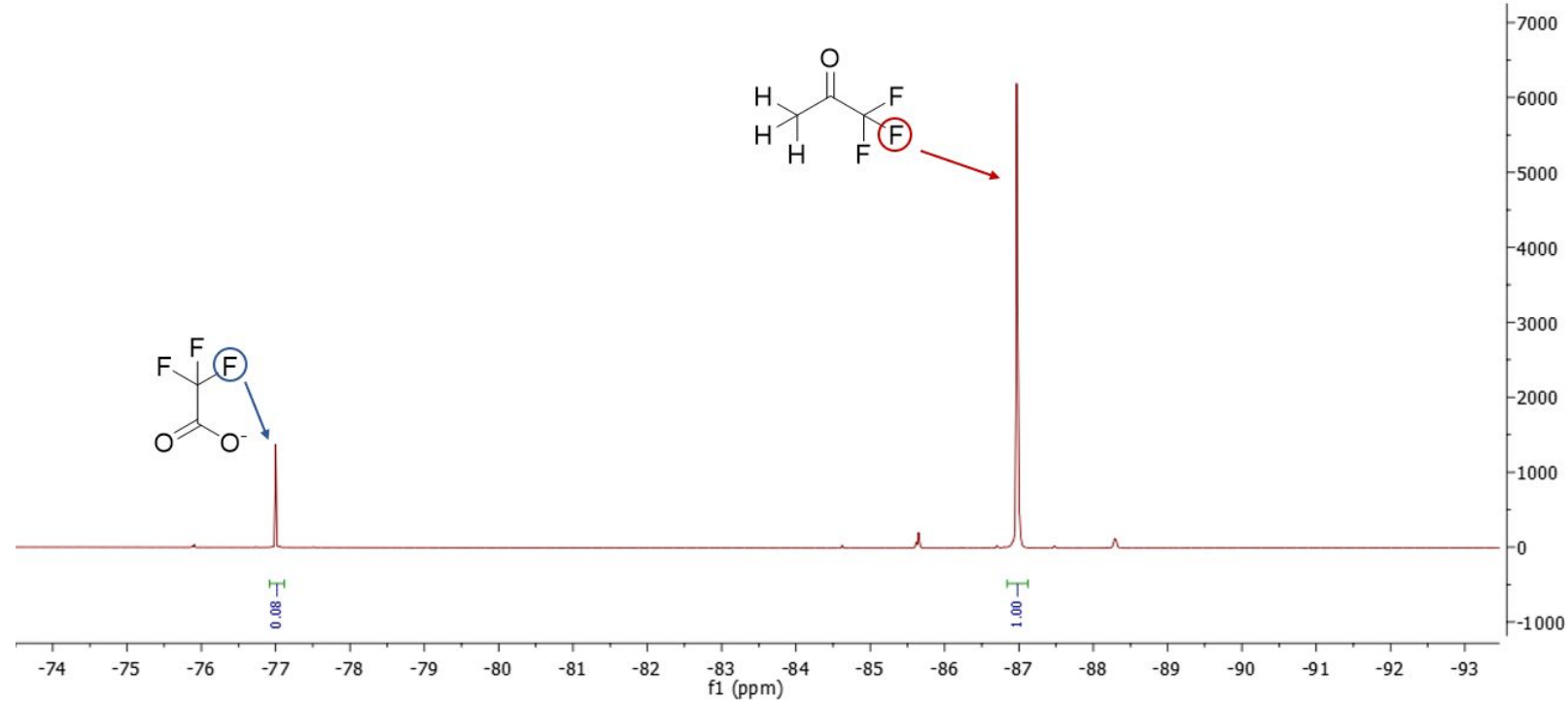

Figure S21: ${ }^{19} \mathrm{~F}$ NMR spectrum of UiO-66 modulated with 18 eq of trifluoroacetic acid following digestion with $\mathrm{NaOH}$ in D20. The digested sample has 1,1,1-trfluoroacetone added as a reference needed to relate the concentration of trifluoroacetic acid to the linker. The integration of the 1,1,1trifluoroacetone was set to one. All residual modulator quantifications calculations utilized these peaks for samples synthesized with a trifluoroacetic acid modulator. 


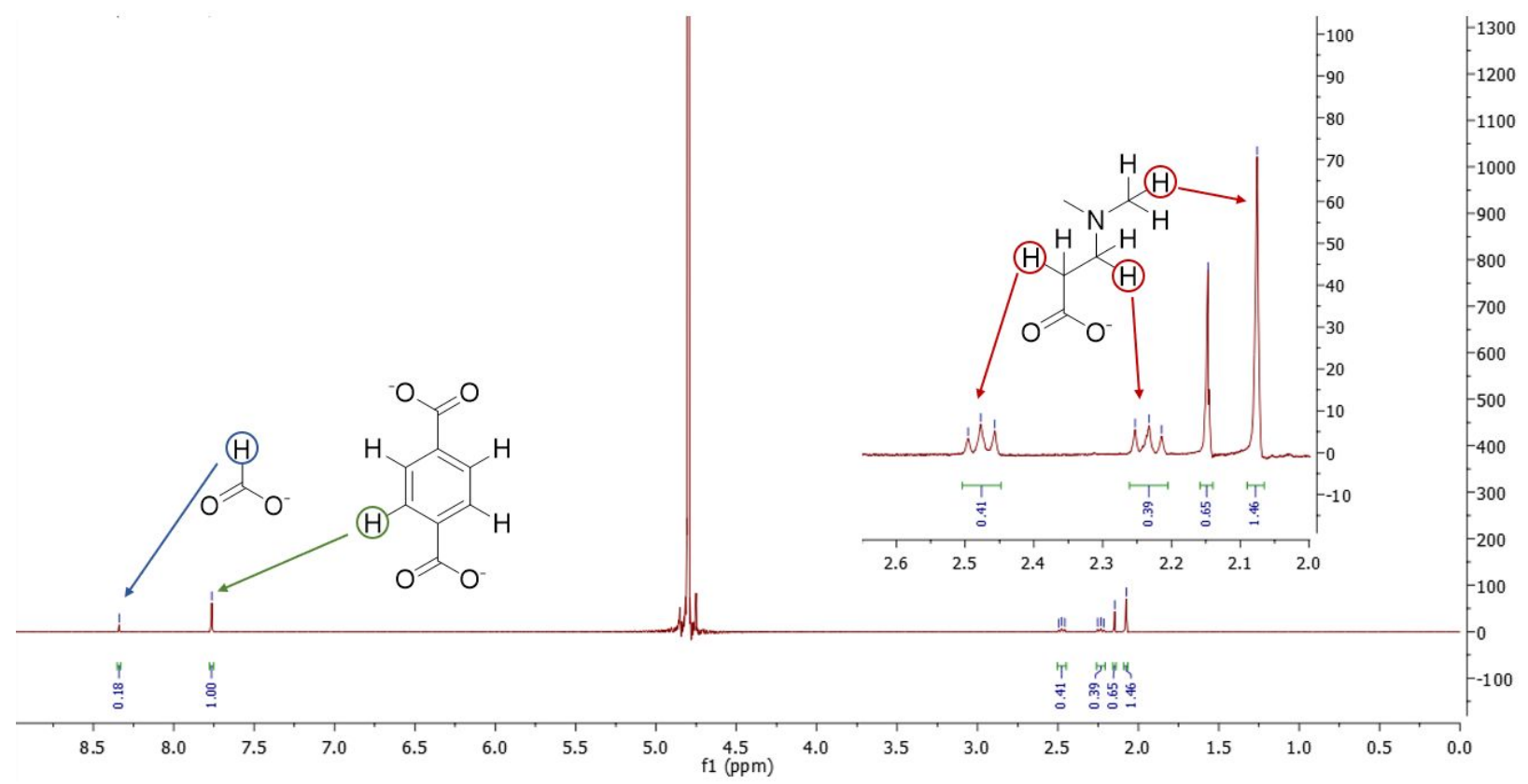

Figure S22: ${ }^{1} \mathrm{H}$ NMR spectrum of UiO-66 modulated with 18 eq of acrylic acid (converted to 3-DMAP acid) following digestion with $\mathrm{NaOH}$ in D20. Insert highlights the residual modulator peaks associated with 3-DMAP and acetone solvent left in the void space. All residual modulator quantifications calculations utilized these peaks for samples synthesized with an acrylic acid modulator. 


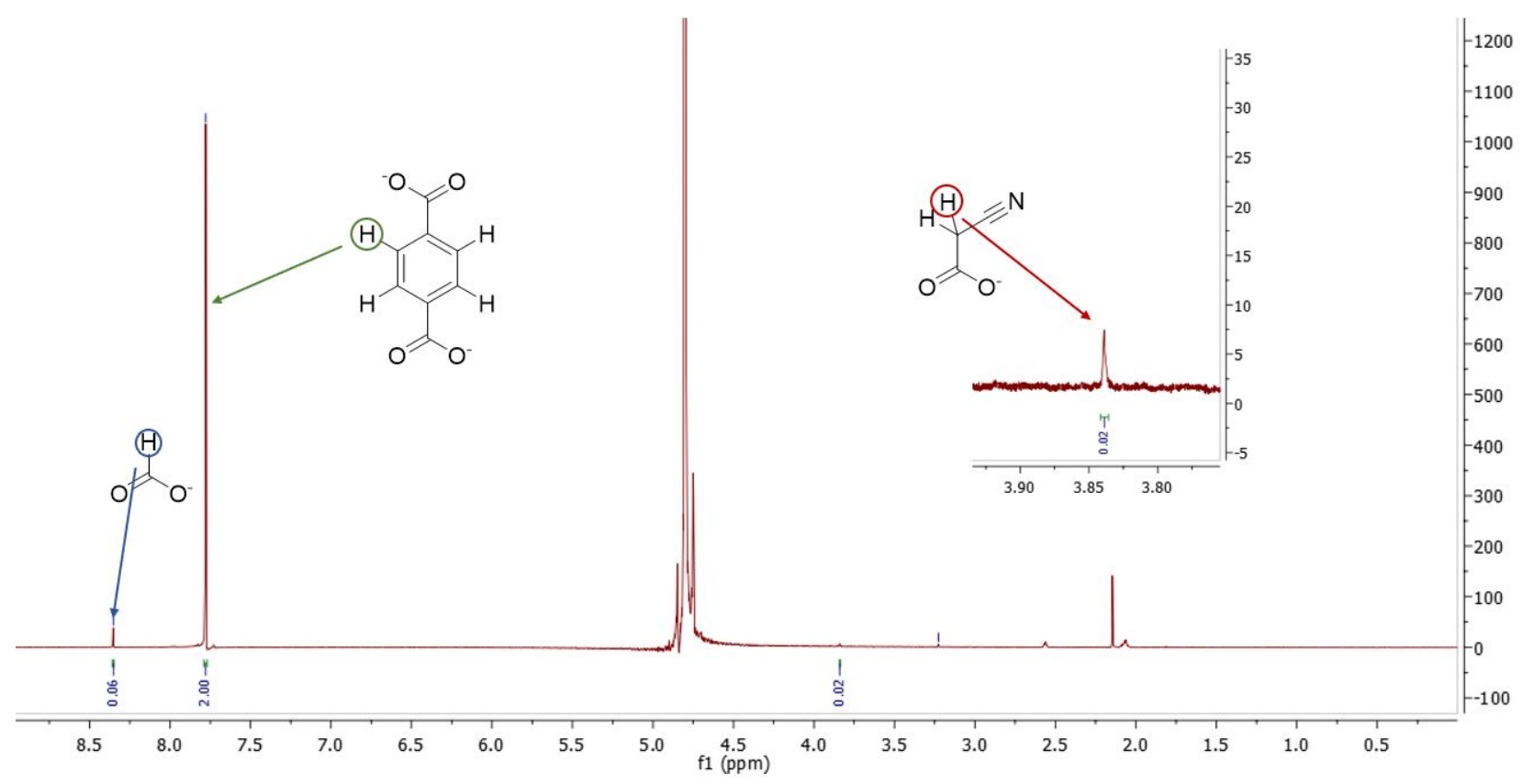

Figure S23: ${ }^{1} \mathrm{H}$ NMR spectrum of UiO-66 modulated with 6 eq of cyanoacetic acid following digestion with $\mathrm{NaOH}$ in D2O. Insert highlights the residual modulator peak associated with the residual cyanoacetic acid left coordinated within the MOF. All residual modulator quantifications calculations utilized these peaks for samples synthesized with a cyanoacetic acid modulator.

\section{3-dimethylaminopropanoic (DMAP) formation}
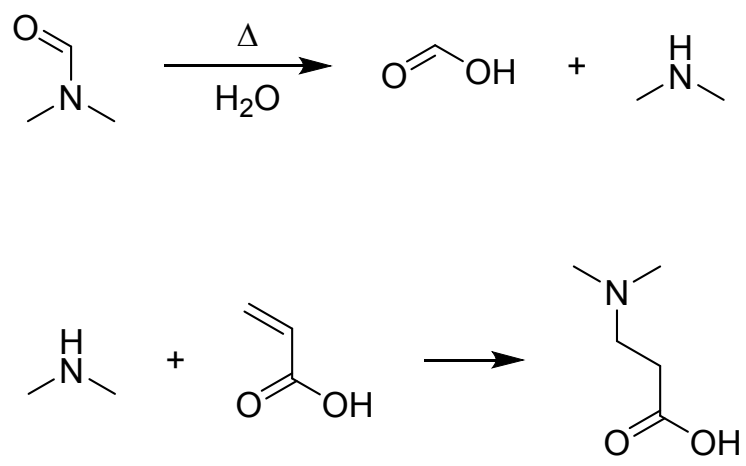

Figure S24: Propose source of 3-dimethylaminopropanoic (DMAP) from the thermal degradation of the $\mathrm{N}, \mathrm{N}$-dimethylformamide solvent and the presence of the acrylic acid modulator through a Michael reaction. 


\section{Computational Data}

Table S04: Binding energies (kJ/mol) for $\mathrm{SO}_{2}$ with molecular and residual modulator with a PBE functional, described by Perdew, Burke, and Ernzerhof ${ }^{3,4}$ and hybridized by Adamo. ${ }^{5}$

\begin{tabular}{|c|c|c|c|}
\hline \multirow{2}{*}{ Modulator } & \multicolumn{2}{|c|}{ Binding Energy (kJ/mol) } & \multirow{2}{*}{ Energy Change } \\
\cline { 2 - 3 } & Modulator & Residual Modulator & -0.82 \\
\hline Acetic acid & -16.61 & -17.43 & 8.09 \\
\hline Trifluoroacetic acid & -17.95 & -9.86 & -86.19 \\
\hline Cyanoacetic acid & -15.55 & -101.75 & -44.45 \\
\hline $\begin{array}{c}\text { Acrylic acid / 3-DMAP } \\
\text { acid }^{*}\end{array}$ & -9.76 & -54.21 & \\
\hline
\end{tabular}

*Acrylic acid modulator converts to a 3- DMAP residual modulator inside the UiO-66 framework (see discussion above) 
a).

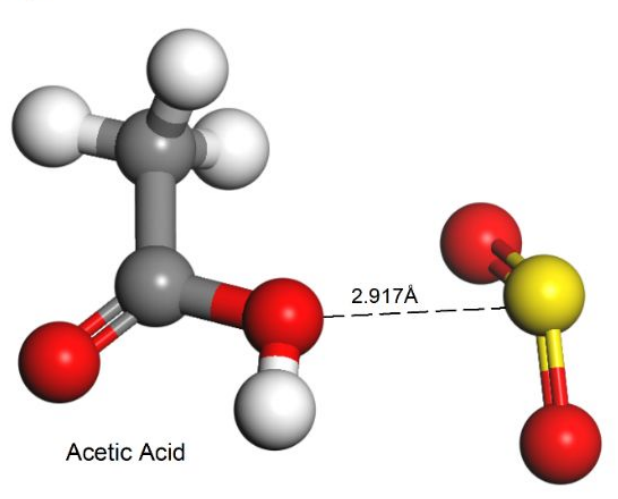

b).

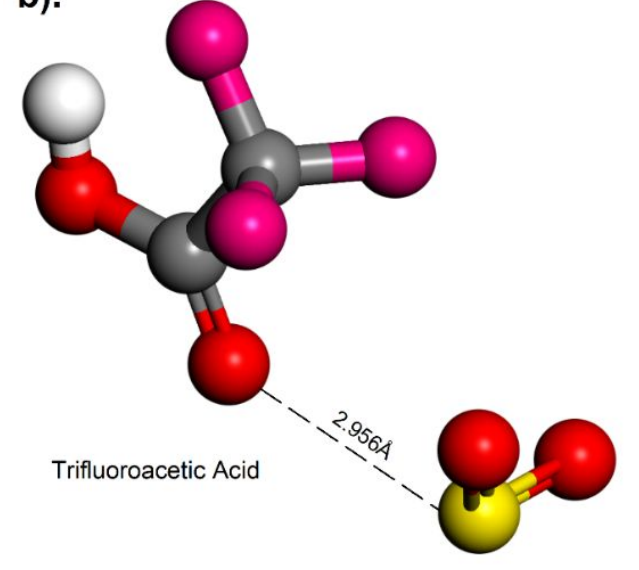

c).

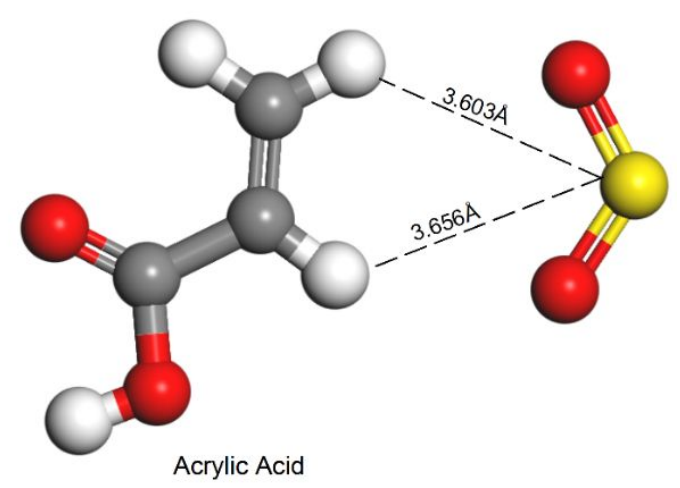

Figure S25: Snapshots of $\mathrm{SO}_{2}$ binding with (a) acetic acid, (b) trifluoroacetic acid, and (c) acrylic acid molecules. Colors: oxygen (red), carbon (grey), fluorine (pink), sulfur (yellow), hydrogen (white) 
a).

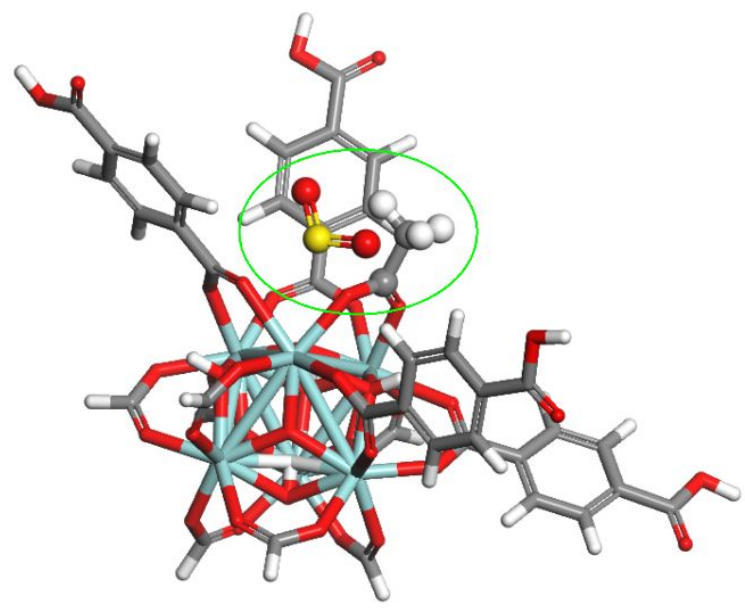

b).

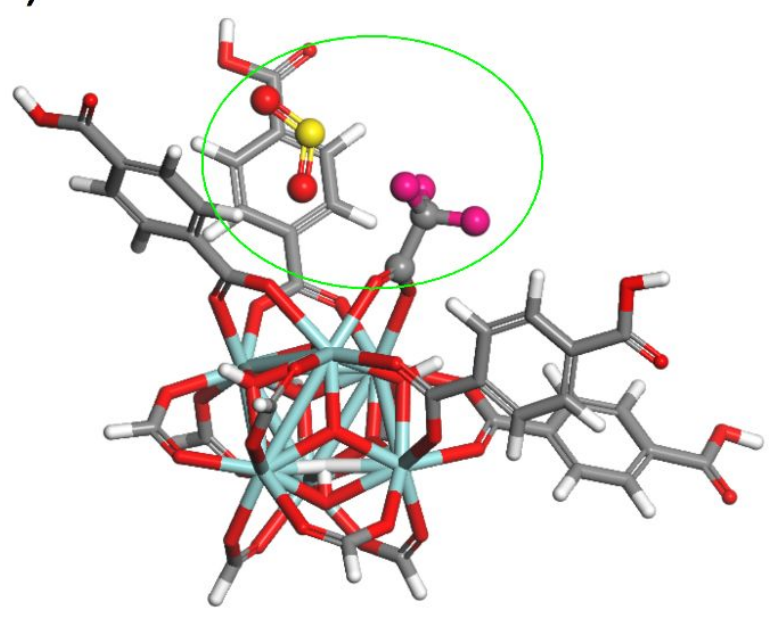

c).

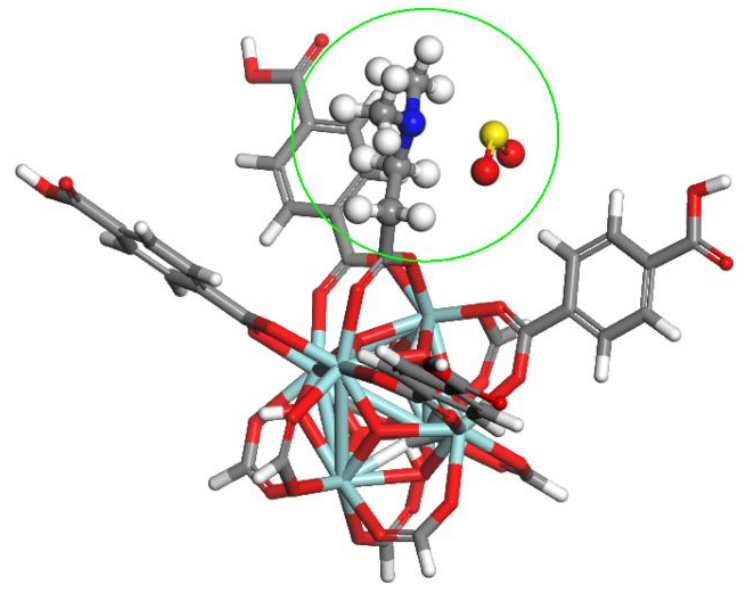

Figure S26: Snapshots of $\mathrm{SO}_{2}$ binding with the residual modulators from (a) am acetic acid modulator (b) a trifluoroacetic acid modulator, and (c) 3- DMAP residual modulator. Colors: oxygen (red), carbon (grey), fluorine (pink) nitrogen (blue), sulfur (yellow), zirconium (teal), hydrogen (white 
1. Cavka, J. H.; Jakobsen, S.; Olsbye, U.; Guillou, N.; Lamberti, C.; Bordiga, S.; Lillerud, K. P., A New Zirconium Inorganic Building Brick Forming Metal Organic Frameworks with Exceptional Stability. Journal of the American Chemical Society 2008, 130 (42), 13850-13851.

2. Shearer, G. C.; Chavan, S.; Bordiga, S.; Svelle, S.; Olsbye, U.; Lillerud, K. P., Defect Engineering: Tuning the Porosity and Composition of the Metal-Organic Framework UiO-66 via Modulated Synthesis. Chemistry of Materials 2016, 28(11), 37493761.

3. Perdew, J. P.; Burke, K.; Wang, Y., Generalized gradient approximation for the exchange-correlation hole of a many-electron system. Physical Review B 1996, 54 (23), 16533-16539.

4. Perdew, J. P.; Burke, K.; Ernzerhof, M., Generalized Gradient Approximation Made Simple [Phys. Rev. Lett. 77, 3865 (1996)]. Physical Review Letters 1997, 78 (7), 1396-1396.

5. Adamo, C.; Barone, V., Toward reliable density functional methods without adjustable parameters: The PBE0 model. The Journal of Chemical Physics 1999, 110 (13), 6158-6170. 